\title{
Produção e Ilustração de Textos com Suporte Digital na Educação Infantil
}

\author{
Hanna Almeida Sousa1, Maria Auricélia da Silva2, José Aires de Castro Filhoz \\ 1Geografia - Universidade Federal do Ceará (UFC) - Campus do Pici - Bloco 911- \\ Fortaleza-CE - Brasil
}

2Unidade Universitária de Educação Infantil Núcleo de Desenvolvimento da Criança Universidade Federal do Ceará (UFC) - Campus do Pici - Bloco 859 - Fortaleza-CE Brasil

3Instituto UFC Virtual - Universidade Federal do Ceará (UFC) - Campus do Pici Bloco $9011^{\circ}$ andar, Fortaleza-CE

hannaalso04@gmail.com, silvauricelia@gmail.com, aires@virtual.ufc.br

\begin{abstract}
This work discusses the production of fairy tales by five-year-old children, using digital support. General objective: favor the production of fairy tales with digital support in children's education. Specific objectives: go along with textual production using digital means in children's education; verify if the use of a digital resource favors the production of fairy tales in Children's Education. The locus of the research was a public school for Children's Education, with a qualitative approach as support for data analysis. The use of a digital resource favored the production of fairy tales in Child Education, provided the production of texts and sketches.
\end{abstract}

Resumo. Este trabalho discute a produção de histórias por crianças de cinco anos de idade, usando suporte digital. Objetivo geral: favorecer a produção de histórias com suporte digital na Educação Infantil. Objetivos especificos: acompanhar a produção textual com uso de um recurso digital na Educação Infantil; verificar se a utilização de um recurso digital favorece a produção de histórias na Educação Infantil. O locus da pesquisa foi uma escola pública de Educação Infantil, tendo a abordagem qualitativa como suporte à análise dos dados. A utilização de um recurso digital favoreceu a produção de histórias na Educação Infantil, proporcionou a produção de textos e ilustrações.

\section{Introdução}

As crianças, em suas experiências e contatos com o mundo, desenvolvem interesse pelas tecnologias digitais presentes em seu cotidiano e demonstram grande facilidade de utilizálas. Por isso, é importante que, já na Educação Infantil, as Tecnologias Digitais da Informação e Comunicação (TDIC) sejam utilizadas como ferramentas que contribuam com a aprendizagem e o desenvolvimento das crianças, de forma lúdica, com vistas à ampliação de suas experiências no âmbito escolar. 
As Diretrizes Curriculares Nacionais para a Educação Infantil - DCNEI [Brasil 2010] recomendam que as práticas pedagógicas na Educação Infantil possibilitem a utilização de recursos tecnológicos, tais como o uso de gravadores, projetores, computadores, máquinas fotográficas, entre outros. Tal proposta aproxima essas ferramentas do processo de ensino e aprendizagem, tornando-o mais lúdico e atrativo, recomendações também presentes na Base Nacional Comum Curricular [Brasil 2017].

Diante dessas recomendações, faz-se necessário inserir recursos tecnológicos nas práticas pedagógicas vivenciadas na Educação Infantil, a fim de oferecer múltiplas linguagens e diferentes recursos para que as crianças aprendam e se desenvolvam no mundo letrado e tecnológico.

A partir dessas questões, este trabalho discute a produção de histórias com suporte digital por crianças de cinco anos de idade. O objetivo geral desta pesquisa consistiu em favorecer a produção de textos com suporte digital na Educação Infantil. Os objetivos específicos foram assim definidos: acompanhar a produção de textos com uso de um recurso digital na Educação Infantil e verificar se a utilização de um recurso digital favorece a produção de histórias na Educação Infantil.

O locus desta pesquisa foi uma escola pública de Educação Infantil, e a abordagem qualitativa de caráter interpretativo apoiou a análise dos dados coletados por meio da observação participante.

A realização deste trabalho indicou que o uso de um recurso digital como suporte ao trabalho pedagógico na Educação Infantil favoreceu a produção de histórias e a criação de ilustrações a partir das ferramentas disponibilizadas no recurso digital.

A seguir, será apresentada a fundamentação teórica que ofereceu suporte à realização deste trabalho.

\section{Crianças, tecnologias digitais e produção textual}

$\mathrm{Na}$ sociedade atual, as crianças têm acesso a diversos recursos tecnológicos e, em consequência, demonstram facilidade quanto ao uso desses dispositivos. Assim, convém favorecer o acesso das crianças da Educação Infantil às tecnologias digitais para que ampliem suas experiências.

Em razão das vivências em uma sociedade que utiliza recursos tecnológicos para a realização de atividades cotidianas, facilmente as crianças aprendem a usar smartphones, tablets, laptops e outros recursos. Sobre essas relações que se estabelecem entre as pessoas e as tecnologias, Kenski (2007 p. 21) afirma que "o homem transita culturalmente mediado pelas tecnologias que lhe são contemporâneas. Elas transformam sua maneira de pensar, sentir e agir".

As Diretrizes Curriculares Nacionais para a Educação Infantil (DCNEI) recomendam a realização de atividades que "possibilitem a utilização de gravadores, projetores, computadores, máquinas fotográficas e outros recursos tecnológicos e midiáticos" [Brasil 2010 p. 27]. Faz-se necessário dar especial atenção aos aspectos lúdicos e às interações entre as crianças, entre estas e os professores, quando recursos tecnológicos são utilizados como apoio pedagógico, pois as práticas pedagógicas desenvolvidas devem priorizar as interações e as brincadeiras, eixos norteadores do trabalho na Educação Infantil, estabelecidos para garantir a vivência de amplas experiências propostas nas DCNEI [Brasil, 2010]. 
Na Base Nacional Comum Curricular (BNCC), o acesso à tecnologia é colocado como um aspecto relevante da criação e expressão humanas, como também o são as artes, a escrita e a ciência. A BNCC estabelece, dentre os Direitos de Aprendizagem e Desenvolvimento na Educação Infantil, o direito de explorar "movimentos, gestos, sons, formas, texturas, cores, palavras, emoções, transformações, relacionamentos, histórias, objetos, elementos da natureza [...] em suas diversas modalidades: as artes, a escrita, a ciência e a tecnologia" [Brasil 2017 p. 34].

No campo de experiências Traços, sons, cores e formas, a BNCC ressalta a importância da convivência das crianças com diferentes manifestações artísticas, culturais e científicas, na instituição escolar e fora dela, em âmbito local e universal. Experiências com formas diversas de expressão, em que "as crianças tenham acesso a artes visuais, música, teatro e criem suas próprias manifestações por meio da manipulação de diversos materiais e de recursos tecnológicos" [Brasil 2017 p. 37].

Outro aspecto recomendado desde a Educação Infantil é o convívio com diferentes portadores de texto, nos mais diversos gêneros. As DCNEI orientam que as atividades propostas "possibilitem às crianças experiências de narrativas, de apreciação e interação com a linguagem oral e escrita, e convívio com diferentes suportes e gêneros textuais orais e escritos" [Brasil 2010 p. 25].

Comumente, crianças de até cinco anos de idade ainda não leem nem escrevem de forma convencional, mas são capazes de produzir textos, tendo os professores como escribas. Girão e Brandão (2011) enfatizam que o fato de as crianças ainda não saberem escrever seus textos não significa que não sejam capazes de produzi-los. O registro das ideias das crianças pode ser feito por um escriba ou por ela mesma, conforme os conhecimentos de que já disponha no momento da produção de suas ideias.

Esse tipo de atividade alinha-se com a recomendação do Referencial Curricular para a Educação Infantil, quando enfatiza a importância do registro das ideias das crianças por um escriba: "É em atividades desse tipo que elas começam a participar de um processo de produção de texto escrito, construindo conhecimento sobre linguagem antes mesmo que saibam escrever autonomamente" [Brasil 1998 p. 146]. A despeito de haver decorrido um período considerável desde que esse documento foi produzido e divulgado, essa orientação continua atual porque as crianças vivem em um mundo letrado, por conseguinte apropriam-se facilmente do código escrito, pois têm acesso a diversos portadores de texto em seu cotidiano.

Os Indicadores de Qualidade na Educação Infantil fazem referência à "multiplicidade de experiências e linguagens" a partir das quais é possível observar se "as crianças são incentivadas a produzir textos mesmo sem saber ler e escrever" [Brasil 2009 p. 43]. Esse documento coloca a produção de textos como um dos índices de qualidade no trabalho pedagógico desenvolvido com crianças desse nível de escolaridade.

No campo de experiências Oralidade e Escrita, a BNCC reforça que a Educação Infantil constitui a etapa de apropriação da linguagem, razão pela qual "desde cedo, a criança manifesta desejo de se apropriar da leitura e da escrita" [Brasil 2017 p. 37]. Nesse processo, os recursos tecnológicos podem favorecer o contato com as letras do alfabeto e os numerais nos teclados de desktops, laptops, tablets e smartphones, facilitando a aproximação com esses símbolos gráficos. 
A literatura acerca da produção textual com suporte digital na Educação Infantil ainda é limitada e, comumente, não são encontrados registros correlatos das atividades apresentadas neste trabalho. Tanto que o recurso digital utilizado nesta investigação é recomendado para crianças a partir do $1^{\circ}$ do ano do Ensino Fundamental, conforme consta no Guia do Professor, que acompanha o referido recurso.

Oliveira (2009) pesquisou a criação de histórias com o suporte do software Teatro no Computador em turmas de Educação Infantil. Esse estudo ressalta a importância da utilização desse recurso para o desenvolvimento de habilidades como criatividade, imaginação, interpretação crítica, concentração e expressão desde a Educação Infantil.

Alguns trabalhos voltados para a Educação Infantil estão mais diretamente ligados à formação de professores, como as experiências descritas por Blasques et al (2007) e Machado et al (2016), que trabalharam a leitura e a produção textual na formação de professores do Ensino Fundamental e da Educação Infantil, respectivamente. Esses trabalhos evidenciam preocupação com a produção textual das crianças, pois oferecem formação aos professores para que desenvolvam práticas pedagógicas nessa perspectiva.

Estudos de Bergamasco e Bergamasco (2013) apresentaram mais desafios do que avanços quanto à implantação de tecnologias digitais na Educação Infantil, em São Paulo. Para as autoras, os desafios em relação às práticas pedagógicas com suporte digital na Educação Infantil dizem respeito, sobretudo, à inexistência de políticas públicas e à falta de formação docente, a despeito de os dados apontarem para o reconhecimento dos professores sobre as possibilidades de aprendizagem com uso de recursos digitais.

Sobreira, Nunes e Morassi (2013) utilizaram recursos tecnológicos com crianças do Ensino Fundamental para a construção de uma história não linear, a fim de promover a reconstrução de narrativas, oferecendo novas hipóteses, conforme o desenrolar do enredo e buscando oferecer maior interatividade com o leitor. Nesse trabalho, a perspectiva de estimular a produção textual também está presente, contudo o trabalho foi realizado com crianças maiores, portanto do Ensino Fundamental.

Nakano et al (2018) relatam uma experiência de integração de tecnologias digitais ao ensino-aprendizagem da temática Linguagem Oral e Escrita. A partir do uso de recursos digitais com crianças do $5^{\circ}$ ano do Ensino Fundamental, os pesquisadores constataram que a integração dessas tecnologias ao trabalho com a linguagem oral e escrita aumentou o interesse e a motivação das crianças e melhorou a compreenssão dos conteúdos ou temas abordados. A despeito de essa pesquisa ter sido realizada com crianças do Ensino Fundamental, percebe-se que o fato de utilizar recursos digitais no trabalho pedagógico gerou resultados positivos quanto à linguagem oral e escrita propriamente e em relação à motivação das crianças para o trabalho pedagógico.

Diante do exposto, percebe-se que a produção textual desde a Educação Infantil constitui atividade de extrema importância a ser desenvolvida com as crianças. Os documentos legais e a literatura indicam que o suporte digital pode ser um recurso favorável, pois faz parte do cotidiano das crianças e se mostra bastante apreciado por elas.

É na tentativa de refletir sobre a produção textual com o uso de recursos digitais na Educação Infantil que este trabalho se constitui. Para a continuidade das discussões, será apresentado o percurso metodológico. 


\section{Percurso metodológico}

O paradigma interpretativo enfatiza o sentido que as coisas têm dentro de um determinado contexto, já que "as ações podem ser melhor compreendidas quando são observadas no seu ambiente habitual de ocorrência" [Bogdan e Biklen 1994 p. 48]. Por essa razão, esse paradigma foi adotado neste trabalho com o intuito de compreender e captar a percepção infantil sobre as ações vivenciadas,

Para dar suporte a esta pesquisa, foi adotada a abordagem qualitativa de caráter interpretativo porque permite ao pesquisador organizar os dados coletados durante a realização das atividades propostas, identificar padrões de comportamento passíveis de serem transformados em categorias de análise, delimitar as características de cada categoria e interpretar o que os dados revelam [Bogdan e Biklen 1994 p. 48].

A observação participante favoreceu a coleta de dados por meio do Diário de Campo, dos registros das falas das crianças e da percepção das escolhas que faziam durante a produção de suas histórias. O locus da pesquisa foi a Unidade Universitária de Educação Infantil Núcleo de Desenvolvimento da Criança (UUNDC/UFC). Este trabalho foi realizado com 26 (vinte e seis) crianças de cinco anos de idade, portanto duas turmas (Infantil 5A e Infantil 5B), no ano letivo de 2018.

Inicialmente, foi necessário um contato direto com as crianças, de modo a estabelecer interações para, assim, conhecer seus interesses e criar um ambiente favorável à realização da atividade. Como as crianças não estavam familiarizadas com o uso do mouse para a produção de desenhos, cada criança utilizou as ferramentas de desenho disponíveis na atividade 2 do Objeto de Aprendizagem (OA) Histórias Fantásticas por três vezes para o desenho livre antes das produções que ilustraram os textos criados.

Depois, as crianças eram convidadas a criar histórias, individualmente, tendo como suporte a mediação dos pesquisadores e o OA Histórias Fantásticas, desenvolvido pelo Grupo de Pesquisa e Produção de Ambientes Interativos e Objetos de Aprendizagem (PROATIVA), da Universidade Federal do Ceará (UFC).

O referido recurso digital, disponível no endereço eletrônico http://www.proativa.vdl.ufc.br/oa/historias, adequa-se a crianças dos primeiros anos do Ensino Fundamental, que já leem e escrevem convencionalmente, conforme consta no material didático disponibilizado aos usuários. Contudo, pelo fato de permitir a produção de textos e como há uma lacuna em relação à existência desse tipo de recurso para a Educação Infantil, o OA Histórias Fantásticas foi utilizado por crianças da Educação Infantil.

Para a produção textual, foi utilizada a Atividade 2 do OA Histórias Fantásticas, na qual as crianças deveriam criar uma história e, depois, ilustrá-la (Figura 1). Esse tipo de atividade permite total liberdade e autoria no processo de criação do enredo. 


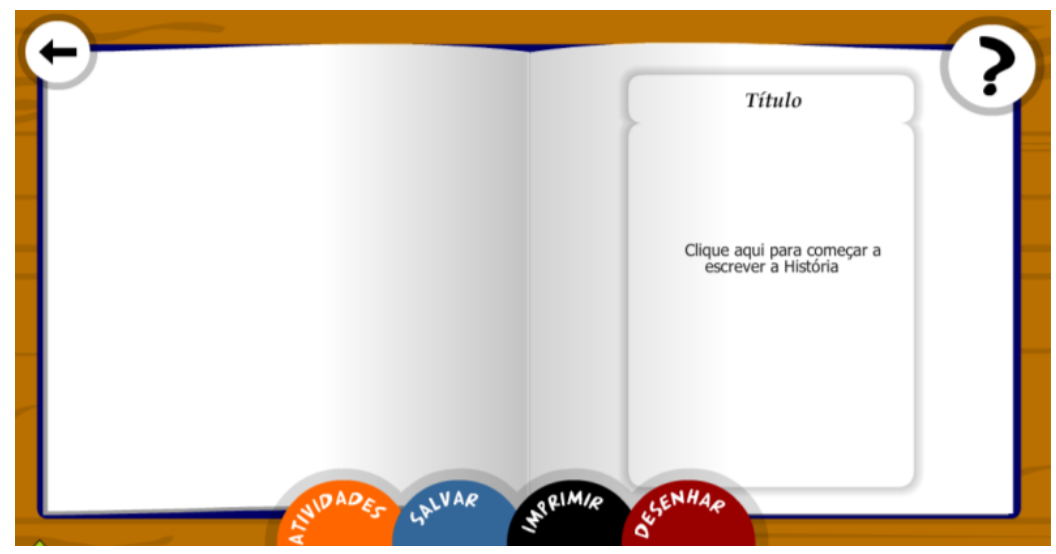

Figura 1. Tela para criação da história

Contudo, em se tratando do uso de desktops e mouses, a atividade poderia tornarse difícil para as crianças, familiarizadas com as telas de toque dos smartphones e tablets que utilizam no cotidiano. Além disso, a proposta da atividade (prevista no OA Histórias Fantásticas) era que as crianças criassem a história antes da produção das ilustrações, sequência comumente contrária às produções infantis, em que as crianças criam seus desenhos e, posteriormente, comentam as ideias contidas em suas representações.

A produção do texto e dos desenhos era livre, mas os pesquisadores liam repetidas vezes o texto já produzido para que as crianças tivessem ideia de como estava sendo construída a narrativa, perguntavam a elas o que estava acontecendo nas cenas produzidas e, somente ao final da produção do texto, perguntavam às crianças como seria o título (ou "nome") da história que elas haviam criado. Como a atribuição de título a uma narrativa é algo que requer grande capacidade de síntese, pode constituir uma atividade complexa para crianças pequenas.

Para a criação de ilustrações, as crianças poderiam usar diversos recursos, utilizando o mouse, como pode ser observado na Figura 2.

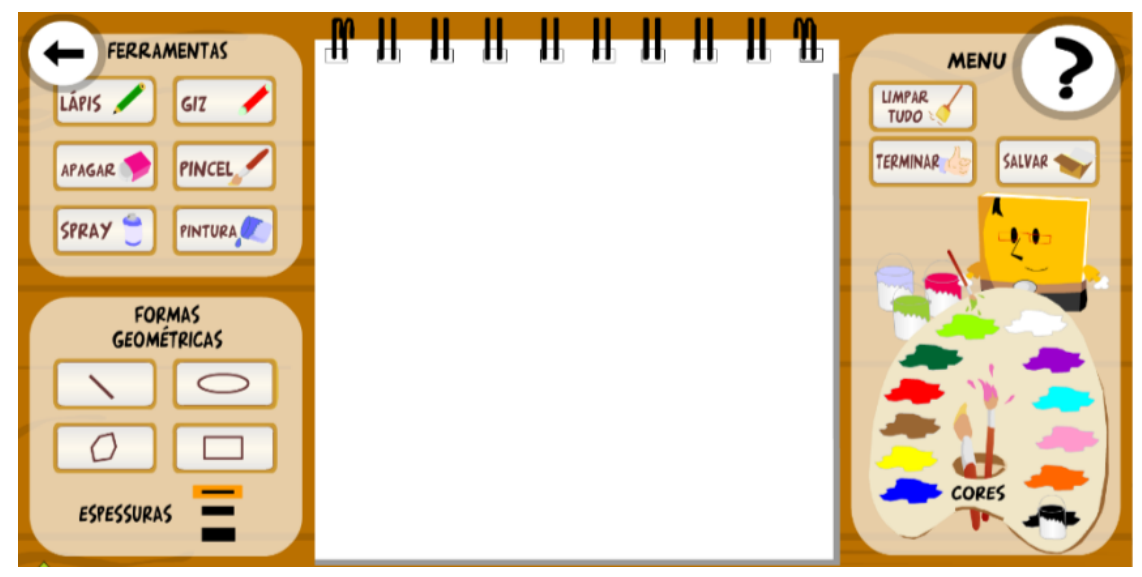

Figura 2. Tela para ilustração da história

Nas Figuras 3 e 4 podem ser observadas histórias criadas e ilustradas pelas crianças, usando como suporte as ferramentas disponíveis na Atividade 2 do OA Histórias Fantásticas. 


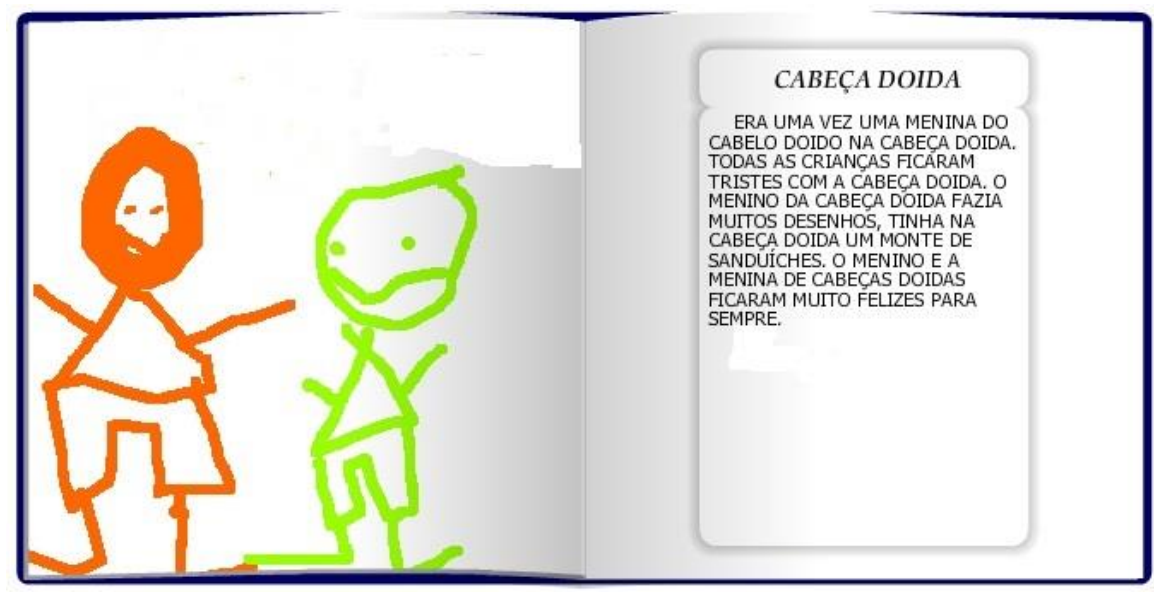

Figura 3. História produzida e ilustrada por JS

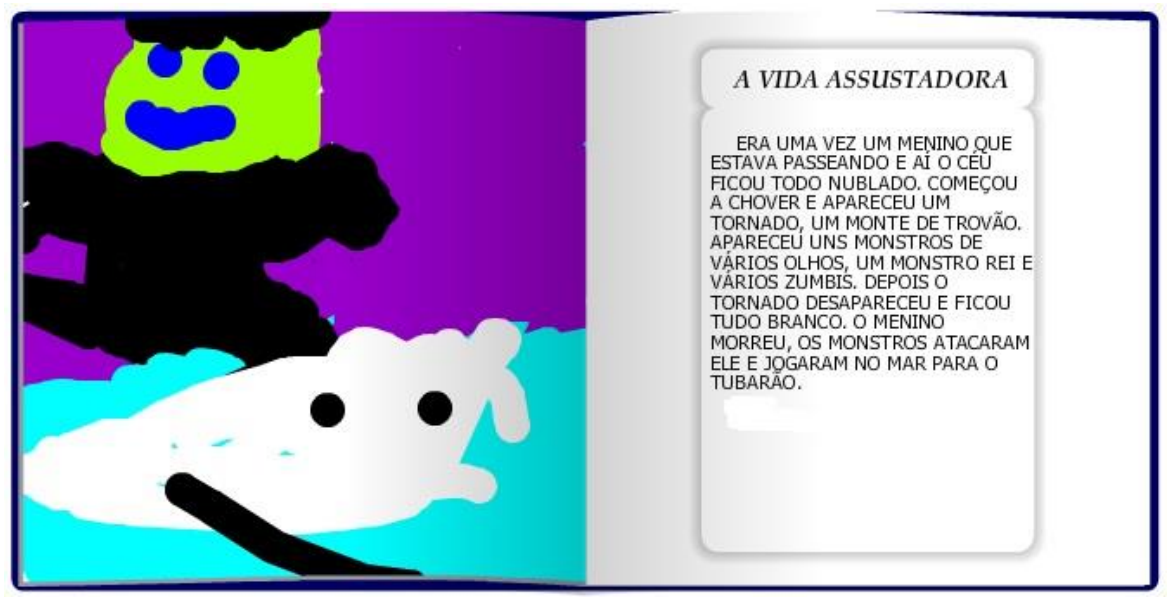

Figura 4. História produzida e ilustrada por LF

Após a produção das histórias, foram organizados dois livros digitais intitulados Histórias Fantásticas volume 6 e Histórias Fantásticas volume 7, com as produções das turmas Infantil 5A e Infantil 5B, respectivamente. A publicação desses livros dá continuidade a uma coleção que já vem sendo produzida e publicada anualmente pela instituição, com produções das crianças utilizando a Atividade 1 desse recurso digital.

A publicação online foi divulgada para a comunidade escolar, a fim de valorizar a produção textual das crianças perante os integrantes da UUNDC, os familiares e, ao mesmo tempo, incentivar a cultura digital no âmbito da unidade escolar. Os referidos livros digitais estão disponíveis nos endereços eletrônicos encurtador.com.br/tIPYZ e encurtador.com.br/artHW e podem ser acessados facilmente.

\section{Resultados e discussão}

A realização deste trabalho na Educação Infantil revelou que as vinte e seis (26) crianças envolvidas demonstraram grande facilidade de usar o computador e o OA Histórias Fantásticas, o que comprova pesquisas de Sancho (2006), Prensky (2001) e Kenski (2007) acerca da facilidade com que crianças e jovens acessam os recursos digitais presentes em seu cotidiano. 
O OA Histórias Fantásticas permitiu a autoria e a criatividade, pois as crianças tinham diante de si uma tela branca com ferramentas de ilustração à sua disposição, de modo que sua imaginação fluía livremente. A fluência de ideias e a criação do enredo ratificaram a ideia de que as crianças gostam de ouvir, (re)contar e criar suas próprias histórias, mesmo sem saberem ler nem escrever convencionalmente [Girão e Brandão 2011].

A possibilidade de vivenciar experiências de criação e narração de histórias, bem como a aproximação entre as linguagens oral e escrita [Brasil 2010], certamente ampliou as aprendizagens infantis, além de encorajar as crianças para a livre expressão e a produção textual desde a Educação Infantil.

Das vinte e seis (26) crianças envolvidas nesta pesquisa, todas participaram, sendo que vinte e quatro (23) produziram histórias ilustradas; duas (2) produziram apenas ilustrações e uma (1) criou o texto, mas não produziu imagens.

Dentre as vinte e três (23) que produziram textos ilustrados, quatro (4) criaram uma oração ou frase para identificar sua produção e dezenove (19) produziram histórias e ilustrações relativas às histórias criadas. As quatro (4) crianças que colocaram uma frase ou oração produziram, inicialmente, o desenho e, só depois, criaram as frases para identificá-los, invertendo a proposta do recurso digital de, na Atividade 2, produzir o texto e ilustrá-lo depois.

Dos dezenove (19) textos ilustrados, treze (13) crianças atribuíram título à sua produção e seis (6) não o fizeram. A atribuição de título a uma produção é uma atividade complexa para crianças de cinco anos, pois requer grande capacidade de síntese. Em alguns casos, as crianças ficaram tão envolvidas com a narrativa, que não acharam necessário atribuir títulos às histórias, mesmo reconhecendo que toda história tem um nome.

As histórias criadas pelas crianças versaram sobre os seguintes assuntos: praia, partes do corpo humano, passeios que desejavam realizar, aventura, situações vivenciadas pelas crianças no cotidiano, galáxias e planetas, contos de fadas e princesas, animais, personagens de filmes infantis e brincadeiras infantis. Dentre esses, os temas mais abordados foram: situações vivenciadas pelas crianças no cotidiano (4 histórias), praia (6 histórias) e aventura (6 histórias).

Além desses aspectos, a utilização do OA Histórias Fantásticas tornou a produção textual uma atividade divertida porque as crianças usaram o computador e um recurso digital interativo, colorido, com interface amigável e de fácil navegação. A existência de pequenos textos que tinham por finalidade orientar a execução da atividade foi contornada com a mediação dos pesquisadores, que procuraram tornar o momento da produção textual alegre e convidativo, para que as crianças se sentissem livres e pudessem criar seus textos.

\section{Considerações finais}

Os resultados obtidos permitem concluir que as crianças conseguem produzir textos desde a Educação Infantil, razão pela qual a produção de textos deve ser estimulada já nessa etapa da Educação Básica.

As crianças necessitam de um escriba/digitador, pois ainda não leem nem escrevem convencionalmente. Todavia, esse fato não inviabiliza nem dificulta a criação 
de histórias pelas crianças, desde que o mediador as incentive a realizar as etapas com tranquilidade e releia periodicamente o texto já produzido, para que a criança tenha condições de acrescentar ou retirar elementos e aperfeiçoar seu texto.

O suporte digital favoreceu a produção textual porque as ferramentas para criação das ilustrações estavam disponíveis e serviam como apoio à produção infantil. Além disso, o recurso digital utilizado é de simples manuseio, tem uma interface amigável e favorece a aprendizagem lúdica, como devem ser as atividades na Educação Infantil.

Foi necessário, contudo, que as crianças utilizassem as ferramentas de desenho e ilustração três vezes antes da ilustração do texto, a fim de se familiarizarem com o uso do mouse e dos recursos disponíveis, pois estavam utilizando um desktop.

O OA Histórias Fantásticas pode ser utilizado online ou offline, o que facilita o trabalho de professores e pesquisadores, especialmente nas instituições que têm dificuldade de acesso à Internet.

A divulgação do livro digital teve amplo alcance, foi bem aceita pela comunidade escolar e não gerou custos à instituição. As crianças e seus familiares sentiram-se valorizados devido à publicação dos livros digitais e à repercussão positiva que esse trabalho obteve em seu grupo de familiares e amigos, bem como na unidade escolar.

Diante desses aspectos, constata-se que a utilização do OA Histórias Fantásticas favoreceu a produção textual na Educação Infantil e o contato das crianças com os recursos digitais. A despeito de ter sido criado para crianças do Ensino Fundamental, o referido OA pode ser utilizado sem dificuldade por crianças de cinco anos, além de favorecer a ludicidade, a criatividade e a aprendizagem.

\section{Referências}

Bergamasco, E. C.; Bergamasco, L. C. C. (2013) "A utilização das Tecnologias de Informação e Comunicação na Educação Infantil: avanços e desafios". In: II Congresso Brasileiro de Informática na Educação (CBIE 2013) XIX Workshop de Informática na Escola (WIE 2013), UNICAMP, Campinas, São Paulo.

Blasques, Andréa et al. (2007). "Experiência Docente: Ler e Escrever? Com o Computador!" In: Anais do XXVII Congresso da SBC, XIII Workshop de Informática na Escola, Rio de Janeiro.

Bogdan, R; Biklen, S. K. (1994) "Investigação Qualitativa em Educação". Porto, Editora Porto.

Brasil. (1998) "Referencial Curricular Nacional para a Educação Infantil". Ministério da Educação e do Desporto, Brasília, 1998.

(2009) "Indicadores de Qualidade na Educação Infantil". Ministério da Educação/Secretaria da Educação Básica, Brasília, 2009.

(2010) "Diretrizes Curriculares Nacionais para a Educação Infantil". Ministério da Educação. Secretaria de Educação Básica. Secretaria de Educação Básica Brasília: MEC, SEB.

(2017) "Base Nacional Comum Curricular: educação é a base". Ministério da Educação. Secretaria de Educação Básica. Secretaria de Educação Básica - Brasília: MEC, SEB. 
Girão, F. M. P. e Brandão, A. C. P. (2011). Ditando e escrevendo: a produção de textos na Educação Infantil. In: Brandão, A. C. P. e Rosa, E. C. S. "Ler e escrever na Educação Infantil" (Org.). Belo Horizonte, Autêntica Editora, 2ed.

Kenski, V. M. (2007) "Educação e tecnologias: o novo ritmo da informação". Campinas, São Paulo, Papirus.

Machado, E. M. et al. (2016). "A formação do leitor e escritor na perspectiva da inclusão digital de crianças". In: V Congresso Brasileiro de Informática na Educação (CBIE 2016), Anais do XXII Workshop de Informática na Escola (WIE 2016), Uberlândia, Minas Gerais.

Nakano, R.Y. et al. (2018). "Integração de Tecnologias Digitais à Linguagem Oral e Escrita: um estudo de caso no Ensino Fundamental I". In: VII Congresso Brasileiro de Informática na Educação (CBIE 2018), Anais do XXIV Workshop de Informática na Escola (WIE 2018), Fortaleza, Ceará.

Oliveira, Osvaldo Luiz. (2009) "Criando e Recriando Histórias". In: XX Simpósio Brasileiro de Informática na Educação. UFSC/UNIVALI, Florianópolis, Santa Catarina.

Prensky, Marc. (2001) Digital Natives, Digital Immigrants - Part 1. In: Digital Natives, Digital Immigrants. MCB University Press, Vol. 9, No. 5.

Sancho, J.M. (Org.). (2006) "Tecnologias para transformar a educação". Porto Alegre, Artmed.

Silva, Maria Auricélia da; Macedo Filho, José Aloísio; Castro Filho, José Aires de. (2017). "Histórias Fantásticas: produção de textos com suporte digital na Educação Infantil”. In: VI Congresso Brasileiro de Informática na Educação (CBIE 2017), Anais do XXIII Workshop de Informática na Escola (WIE 2017), Recife, Pernambuco.

Sobreira, E. S. R.; Nunes, M.C.; Morassi, S. B. (2013) "Produzindo histórias não lineares: um incentivo à produção escrita e leitura, através do uso contextualizado da tecnologia". In: II Congresso Brasileiro de Informática na Educação (CBIE 2013) XIX Workshop de Informática na Escola (WIE 2013), UNICAMP, Campinas, São Paulo. 